\title{
Interactive comment on "Changes in the properties of deep and intermediate water masses in the Nordic Seas from 1997 to 2016" by Małgorzata Merchel and Waldemar Walczowski
}

\section{Małgorzata Merchel and Waldemar Walczowski}

merchel@iopan.gda.pl

Received and published: 12 October 2018

We would like to thank the Anonymous Referee \#1 for the insightful and constructive review. It will certainly help us improve the quality of our papers in the future. The main Referee objection concerns length and structure of the paper, as well as the lack of citations. Additionally, reviewer list papers which should be cited. Our aim was writing a short paper with a simple message. In our opinion, readers are tired of reading long introductions with a tenth of citations. The short, synthetic paper may be also interesting and valuable. Especially when the message concerns years of measurements. Of course, we are aware that a common system of scientist's evaluation forces putting a 
lot of citation. Langehaug et al., 2012, Somavilla et al., 2013, von Appen et al., 2015 show processes in the Nordic Seas in a different context, besides, the data they present also needs updating. However, we agree with Referee \# 1 that paper needs improving. After this general statement, we answer specific comments of the Anonymous Referee \#1. Ref. \#1. This manuscript presents observations of temperature and salinity over 20 years along a section in the southwestern Fram Strait. Ans. Our idea was rather to present temperature and salinity observations upstream of the Fram Strait. The section along the $76^{\circ} 30^{\prime} \mathrm{N}$ parallel should not be treated as the Fram Strait, not even the south Fram Strait. Ref. \#1. The authors show the increase in temperature and salinity below $500 \mathrm{~m}$. Ans. We also show an increase in temperature at other levels. Ref. \#1 the paper does not present further scientific results or discussion Ans. The discussion will be improved. Ref \#1. ... the existence of a very valuable larger data set, I highly recommend extending the $\mathrm{ms}$. to the full data set, substantially revise text and figures, and submit it to Earth System Science Data Ans. Yes, it is a good idea. But here we want to show part of this data set with a focus to the specific phenomenon. Ref \#1 Raise in temperature of deep Fram Strait/Greenland Sea temperatures and salinities have been shown before and analyses of causes have been discussed for example by Langehaug et al., 2012, Somavilla et al., 2013, von Appen et al., 2015. Ans. Langehaug et al. (2012), analysed the section located in the northern Fram Strait. Also von Appen et al., 2015 described mostly the northern part of the Fram Strait. Our experience shows that this is the most unstable region, with different hydrological conditions than in the area we analysed. From the other hand, Somavilla et al., 2013, shows north Atlantic to $005^{\circ} \mathrm{E}$. Nevertheless, we will improve our article and cite these (and other) papers. Ref \#1. It is unclear why the authors do not use more of their own data, not to speak of other available data, to put their findings into a context. Ans. We agree, that IOPAN has a lot of data. We chose the ' $N$ ' section along the $76^{\circ} 30^{\prime} \mathrm{N}$ because it is our longest time series and is located in an interesting and important region. We used data only from our Institute because we wanted them to be as consistent as possible and performed exactly in the same period of time, from June 22 to July 22 , each of the

OSD

Interactive comment
Printer-friendly version

Discussion paper 
20 presented years. In addition, Walczowski (2014) showed that the salinity and temperature time series at this section may be representative for the larger Nordic Seas region. Ref. \#1The ms. contains a lot of unnecessary information; the text has several repetitions; it is often imprecise, and can be shortened substantially. Ans. We made the text as short as possible, but we will try to be more precise and avoid repetition. Ref \#1. Title: No water masses are analysed Ans. Yes, it is imprecise and title will be changed Rev\#1. Abstract: The 1st paragraph is repetitive and can be summarized in one sentence.... Ans. We made abstract short intentionally, improving paper we will do it more essential. Ref \#1. The second para speaks about recent studies without citing them. Ans. We cite IPCC and Levitus. But we will cite much more. Ref \#1. The last sentence of para 3 ( $p 2$ line 19) is a bizarre statement - how would intermediate layers absorb heat from the surface layers Ans. In the short time scale the geothermal heating of ocean floor is really small (50-200 mW/m2, Sclater et al., 1980; Kadko and Baross, 1995; Stein et al., 1995; Murton et al., 1999). According to Hofmann and Maqueda, 2009 the mean GHF is $100 \mathrm{~mW} / \mathrm{m} 2$, therefore in the global scale, the heat in the intermediate and deep waters may be gained only from surface ocean layer. Here we do not consider the processes of the heat transporting from surface to deep ocean, only results. Ref \#1 surface is here, by the way, defined as reaching down to $500 \mathrm{~m}$ Ans. Yes, better will be 'upper layer', 'upper ocean'. Ref\#1. Fig. 2 can be skipped. Ans. Fig. 2 is very important, but we will leave only results in descriptions and reference to the IPCC report. Ref. \#1 Page 3, Line 10: This statement is again bizarre. Purkey and Johnson (2010), a key paper on ocean warming (that the authors do not refer to), or Desbruyeres et al, 2016, use high-quality data after 2005 in all oceans. Lack of good quality data is mentioned in the IPCC report as well as by Levitus (2012). Purkey and Johnson (2010) and Desbruyeres et al. (2016) analyzed data after 2005 in all oceans, however, not in the Nordic Seas and Arctic Ocean (Fig. 1: Desbruyeres et al. (2016), Fig.8: Purkey and Johnson (2010). "Due to a lack of deep repeat hydrographic data, the Arctic Ocean is not included in the analysis." Desbruyeres et al. (2016) Ref \#1 Fig. 3: Most of the shown data are not used. Why are they shown? Ans. To show that our

OSD

Interactive comment
Printer-friendly version

Discussion paper 
measurements are not incidental and cover bigger region Ref \#1. Page 4, line $13 \mathrm{ff}$ says that data from 1997 until 2016 are used. Then the authors mention 15 sections that obviously are not used. Para 2 says that section $\mathrm{N}$ (the one which finally IS used) provides the longest time series. What does that mean? Is that longer than the 20 years mentioned above? Period 1997-2016 covers 20 mentioned years. Figure 3 presents 'standard' grid of stations covered by us since 2000. Measurements at section 'N' were performed earlier and therefore it is our longest time series. Ref \#1. Line 20ff speaks about water masses (AW) and branches - what does this explain in the chapter "data or methods"? Ans. We describe a region of measurements, the 'data and methods' chapter seems to be good for this. Ref \#1. any information is given on the definition of water masses or where any branches can be seen in the data or why they are of importance here. Ans. We do not analyse water masses (as we describe later), but again, in our opinion, the general information about hydrographic conditions should be provided. The information about the location of both branches is given (eastern over the shelf break, western over the underwater ridge system). Additionally, the position of the Arctic Front is given $\left(007^{\circ} \mathrm{E}\right)$. Ref \#1. Line $\left.26 \mathrm{ff}\right)$ introduces three layers, although the title and the results deal only with two layers. Ans. Indeed the main focus is on the deep and intermediate layers. Should we do not write any word about the upper layer? Ref \#1. What are the Atlantic and Arctic domains Ans. Arctic Waters occur west of the AW domain, with the regions separated by the Arctic Front at $\sim 007^{\circ} \mathrm{E}$. ( $p 4$, paragraph 25) Ref \#1. Which water masses are the authors talking about? Ans. Yes, we agree, the 'water masses' will be changed for simple 'water' Ref\#1 What means the "whole region"? Ans. It is the whole section. Will be improved.

Interactive comment on Ocean Sci. Discuss., https://doi.org/10.5194/os-2018-93, 2018.

Interactive comment 